\title{
TROCA INTERTEMPORAL ENTRE ECONOMIAS DESENVOLVIDAS E EM DESENVOLVIMENTO*
}

\section{Marco Flávio da Cunha Resende}

RESUMO O modelo neoclássico de troca intertemporal conclui pelo aumento do bem-estar concomitantemente à solvência externa intertemporal nas economias que promovem a abertura financeira e comercial. Porém, tal modelo não considera a existência de diferenciais de produtividade entre economias, assumidos em diversas escolas econômicas tais como a ricardiana, cepalina e neo-schumpeteriana. Neste artigo buscou-se avaliar a adequação do citado modelo em relação a um mundo onde os diferenciais de produtividade entre economias estão presentes. Constatouse a inadequação do modelo neoclássico de troca intertemporal quando os citados diferenciais de produtividade são considerados.

Palavras-chave: troca intertemporal; produtividade; economias (não) desenvolvidas

Código JEL: F 41

\section{INTERTEMPORAL TRADE BETWEEN DEVELOPED AND LESS DEVELOPED COUNTRIES}

ABSTRACT Ricardian, ECLAC-UN (Cepal) and Neo-Schumpeterian schools of Economic Thought assume that there are productivity differentials across economies. This paper intends to analyze the power of intertemporal trade neoclassical model to explain the less development countries' intertemporal balance of payments solvency. Conclusions highlight the limits of the neoclassical model in explaining the intertemporal trade when productivity differentials across countries are assumed.

KEY WORDS: intertemporal trade; productivity; (non) development economies

* Artigo recebido em 21 de março de 2005 e aprovado em 6 de dezembro de 2005. O autor agradece a Adriana M. Amado, Maria de Lourdes R. Mollo, Maria Luiza F. Silva e Frederico G. Jayme Jr. pelos comentários e sugestões a uma versão preliminar deste estudo, eximindo-os da responsabilidade pelos erros e omissões porventura remanescentes.

** Professor doutor do Departamento de Economia do Cedeplar/UFMG - Universidade Federal de Minas Gerais, e -mail: resende@cedeplar.ufmg.br 


\section{INTRODUÇÃO}

A absorção de poupança externa é realizada por meio de déficits em conta corrente do balanço de pagamentos. Tal absorção viabiliza incrementos na taxa de investimento doméstica, podendo resultar em ganhos de competitividade e melhoria dos saldos comerciais futuros de um país. Conforme Simonsen e Cysne (1995, cap. 2), argumenta-se que a remuneração do capital é maior nos países em desenvolvimento do que nos países desenvolvidos, pois aqueles teriam maior escassez relativa de capital. "Assim, os capitais se deslocariam naturalmente dos países ricos para os países pobres, contribuindo para a atenuação das desigualdades econômicas internacionais, desde que fossem usados para fins produtivos nos países em desenvolvimento" (Simonsen e Cysne, 1995: 91). Nesta mesma linha de argumentação, Barro et al. (1992: 2) concluem que "assumindo-se que as economias são abertas, o capital se deslocará rapidamente (entre países) para equalizar o produto marginal do capital”.

Segundo Simonsen e Cysne (1995: 91), visto que a absorção efetiva de capitais externos por um país corresponde ao seu déficit em conta corrente do balanço de pagamentos, pode-se concluir que seria natural que os países em desenvolvimento fossem deficitários, e os desenvolvidos, superavitários em transações correntes. A absorção inicial de poupanças externas pelas economias em desenvolvimento seria posteriormente revertida a partir da melhora do saldo comercial dessas economias em função do uso adequado da poupança externa.

Portanto, no que diz respeito aos fluxos de divisas do balanço de pagamentos, seu equilíbrio intertemporal é que é relevante, e não os desequilíbrios em conta corrente ou na conta de capitais autônomos, verificados em algum momento.

O modelo neoclássico de troca intertemporal consolidado na literatura pode ser encontrado em Obstfeld e Rogoff (1996). O objetivo deste artigo é avaliar sua adequação a um mundo onde o paradigma de diferenciais de produtividade entre economias está presente. Neste caso, é necessário fazer a distinção entre economias desenvolvidas e não desenvolvidas. Diferenças entre essas economias não contempladas pelo modelo podem comprometer seus resultados no que se refere às possibilidades de solvência intertemporal do balanço de pagamentos das economias em desenvolvimento e, também, aos seus ganhos de bem-estar. 
Este trabalho conta com 3 seções, além desta introdução. Na seção 1 é apresentado o modelo neoclássico de troca intertemporal baseando-se em Obstfeld e Rogoff (1996). Na seção 2 é avaliada a adequação desse modelo às economias não desenvolvidas no contexto de diferenciais de produtividade entre países. A seção 3 é destinada às conclusões.

\section{O MODELO NEOCLÁSSICO DE TROCA INTERTEMPORAL}

Esse modelo será desenvolvido, a seguir, em suas vertentes de dois períodos, horizonte finito e horizonte infinito. Assumem-se as hipóteses de pequena economia aberta com um só bem, num modelo de agente representativo. ${ }^{1}$ No modelo de dois períodos, com um único bem, sem governo e sem acumulação de capital, a função utilidade do agente representativo é:

$$
U_{1}=u\left(C_{1}\right)+\beta \cdot u\left(C_{2}\right)
$$

onde, $C_{t}=$ consumo no período $t=1,2 ; \beta=$ parâmetro que mede seu desconto subjetivo associado à sua impaciência para consumir, sendo $0<\beta<$ $1 ; u^{\prime}\left(C_{t}\right)>0 ; u^{\prime \prime}\left(C_{t}\right)<0 ; \lim u^{\prime}\left(C_{t}\right)=\infty$. A restrição orçamentária intertem$C \rightarrow 0$

poral do agente representativo é:

$$
C_{1}+C_{2} /(1+r)=Y_{1}+Y_{2} /(1+r)
$$

onde $Y_{\mathrm{t}}=$ produto no período $t=1,2 ; r=$ taxa de juros reais no mercado internacional de capitais no período 1 . Conforme a equação (2), $C_{2}=(1+r)$ $\left(Y_{1}-C_{1}\right)+Y_{2}$, e o valor presente do consumo é igual ao valor presente da produção. Assume-se que o agente representativo tem previsão perfeita do futuro. Seu problema é maximizar (1) sujeito a (2), isto é:

$\operatorname{Max} u\left(C_{1}\right)+\beta \cdot u\left[(1+r)\left(Y_{1}-C_{1}\right)+Y_{2}\right]$ $C_{1}$

A condição de primeira ordem é u' $\mathrm{u}^{\prime}\left(C_{1}\right)=(1+r) \cdot \beta \cdot u^{\prime}\left(C_{2}\right)$

isto é, $\beta \cdot u^{\prime}\left(C_{2}\right) / u^{\prime}\left(C_{1}\right)=1 /(1+r)$

A equação (3) é a equação intertemporal de Euler. ${ }^{2}$ O lado esquerdo de (4) é a taxa marginal de substituição do consumo presente pelo consumo futuro e o lado direito é o preço do consumo futuro em termos do consumo presente. Portanto, o plano ótimo de consumo do agente representativo se dá pela 
combinação da condição de primeira ordem (3) com a restrição orçamentária intertemporal (2). O único preço do modelo é a taxa de juros real $r$.

A conta corrente, que corresponde ao aumento líquido de ativos estrangeiros, é dada por $C A_{t}=B_{t+1}-B_{t}(5)$, onde, $C A_{t}=$ saldo do balanço de transações corrente no período $t ; B_{t}=$ valor dos ativos estrangeiros líquidos no período $t$. Para uma economia sem acumulação de capital e sem governo, $C A_{t}=B_{t+1}-B_{t}=Y_{t}+r \cdot B_{t}-C_{t}^{3}(6)$.

A equação (2) assume implicitamente que $B_{1}=0$, resultando em $C A_{t}$ $=B_{2}=Y_{1}-C_{1}$. Assume-se, também, que ao final do período 2 , que corresponde ao final dos tempos, não há débitos (créditos) a serem saldados pelo agente representativo: $B_{3}=0$. Então:

$$
\begin{aligned}
& C A_{2}=Y_{2}+r . B_{2}-C_{2}=Y_{2}+r .\left(Y_{1}-C_{1}\right)-C_{2}=Y_{2}+r .\left(Y_{1}-C_{1}\right)-\left(Y_{1}-C_{1}\right) \\
& (1+r)-Y_{2} \\
& C A_{2}=-\left(Y_{1}-C_{1}\right)=-B_{2}=-C A_{1}
\end{aligned}
$$

A figura 1 combina a curva de indiferença do agente representativo com sua restrição orçamentária intertemporal, dada por $C_{2}=Y_{2}-(1+r)$ $\left(C_{1}-Y_{1}\right)$. A inclinação das curvas de indiferença será tanto maior quanto menor for $\beta$. O consumo ótimo está no ponto $C$, onde a restrição orçamentária intertemporal é tangente à curva de indiferença. $A$ é o ponto de autarquia: $C_{1}=Y_{1}$ e $Y_{2}=C_{2}$. Os ganhos de utilidade do agente representativo são obtidos com o deslocamento do seu consumo de $A$ para $C$.

Em autarquia, a única taxa de juros real consistente com a equação de Euler (3) é a taxa de juros de autarquia $r_{A}$, tal que:

$$
u^{\prime}\left(Y_{1}\right)=\left(1+r_{A}\right) \cdot \beta \cdot u^{\prime}\left(Y_{2}\right)
$$

isto é, $\beta \cdot u^{\prime}\left(Y_{2}\right) / u^{\prime}\left(Y_{1}\right)=1 /\left(1+r_{A}\right)$

Quando $r_{A}>r$, o preço do consumo futuro de autarquia, dado por $1 /\left(1+r_{A}\right)$, é menor que o preço mundial do consumo futuro: para a economia autárquica, em relação ao resto do mundo o consumo futuro é barato e o consumo presente é caro. Assim, essa economia, ao se integrar ao mercado internacional de capitais, irá importar consumo presente $\left(C A_{1}\right.$ será deficitária) e exportar consumo futuro ( $C A_{2}$ será superavitária), gerando ganhos de utilidade para o agente representativo. Quando $r_{A}<r$, ocorrerá o inverso com os saldos em transações correntes. 
Figura 1

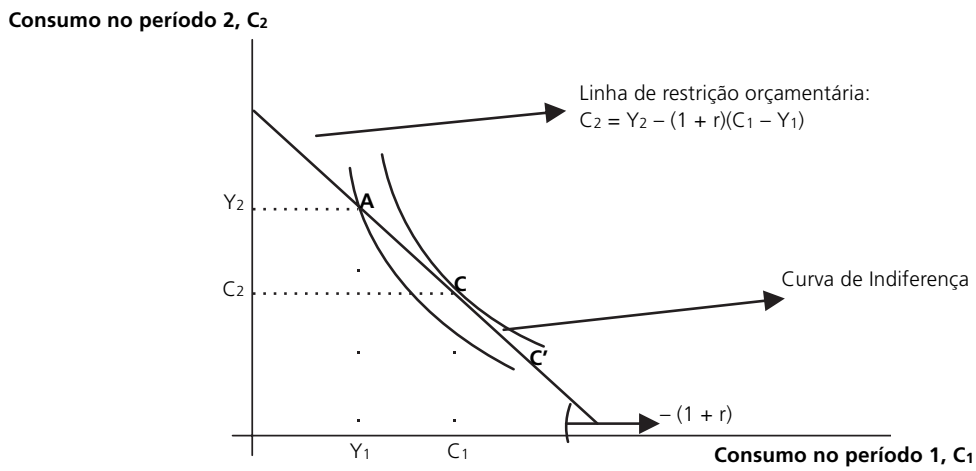

Este resultado está de acordo com o princípio das vantagens comparativas da teoria do comércio internacional, que estabelece que países importam commodities cujos preços de autarquia são elevados em relação aos preços mundiais e exportam aquelas cujos preços de autarquia são relativamente baixos. É a oportunidade de explorar as diferenças de preços pré-comércio internacional que explicam os ganhos com as trocas (mostradas na figura 1) (...) O que produz o ganho é a troca entre diferentes. Quanto maior a diferença, maior o ganho. $O$ único caso em que não há ganho é aquele em que, coincidentemente, $r_{A}=r$. (Obstfeld e Rogoff, 1996: 10)

A inclusão da acumulação de capital e, portanto, dos gastos com investimento no modelo, como também a incorporação ao modelo de um maior horizonte temporal (modelo de horizonte finito) ou de período infinito (modelo de horizonte infinito) não altera esse resultado básico, referente aos ganhos com a troca do consumo no tempo num contexto de solvência intertemporal do balanço de pagamentos. Para acrescentar o investimento ao modelo, assume-se que a produção é função do capital, que é acumulado por meio do investimento. A função de produção é:

$$
Y=F(K)
$$

sendo $K_{1}$ dado historicamente, $F^{\prime}(K)>0, F^{\prime \prime}(K)<0, F(0)=0, \lim _{K \rightarrow 0} F^{\prime}(K)=\infty$.

Uma unidade de capital é criada a partir de uma unidade do bem de consumo, e o capital, depois de usado para a produção dos bens, pode ser "comido". A riqueza privada doméstica no final do período té $B_{t+1}+K_{t+1}$. 


$$
K_{t+1}=K_{t}+I_{t}
$$

Assim,

$$
B_{t+1}+K_{t+1}-\left(B_{t}+K_{t}\right)=Y_{t}+r . B_{t}-C_{t}
$$

Substituindo (10) em (11), $C A_{t}=B_{t+1}-B_{t}=Y_{t}+\mathrm{r} . B_{t}-C_{t}-I_{t}$

Para os períodos 1 e 2 , sendo $B_{1}=B_{3}=0$, a conta corrente é, respectivamente,

$$
\begin{aligned}
& B_{2}=Y_{1}-C_{1}-I_{1} \\
& -B_{2}=Y_{2}+r . B_{2}-C_{2}-I_{2}
\end{aligned}
$$

Resolvendo para $B_{2}$ na equação (14) e substituindo em (13), chega-se à restrição orçamentária intertemporal:

$$
C_{1}+I_{1}+\left(C_{2}+I_{2}\right) /(1+\mathrm{r})=Y_{1}+Y_{2} /(1+r)
$$

O agente representativo maximiza: $U_{1}=u\left(C_{1}\right)+\beta . u\left(C_{2}\right)$ sujeito a (15), sendo $K_{3}=0$, pois para maximizar sua utilidade o agente não permitirá a ocorrência de sobras de capital ao final dos tempos: $I_{2}=-K_{2}$. Usando (15) para eliminar $C_{2}$ de $U_{1}$, o problema do consumidor torna-se:

$$
\operatorname{Max}_{\mathrm{C}_{1}, \mathrm{I}_{1}} u\left(C_{1}\right)+\beta \cdot u\left\{(1+r)\left[F\left(K_{1}\right)-C_{1}-I_{1}\right]+F\left(K_{1}+I_{1}\right)+K_{1}+\mathrm{I}_{1}\right\}
$$

As condições de primeira ordem são:

$$
\begin{aligned}
& u^{\prime}\left(C_{1}\right)=(1+r) \cdot \beta \cdot u^{\prime}\left(C_{2}\right) \\
& (1+r) \cdot \beta \cdot u^{\prime}\left(C_{2}\right)=F^{\prime}\left(K_{2}\right) \cdot \beta \cdot u^{\prime}\left(C_{2}\right)+\beta \cdot u^{\prime}\left(C_{2}\right)
\end{aligned}
$$

Isolando $u^{\prime}\left(\mathrm{C}_{2}\right)$ na equação de Euler para substituir na última equação, tem-se:

$$
F^{\prime}\left(K_{2}\right)=r
$$

Segundo a equação (17), o investimento no período 1 crescerá até o ponto onde seu retorno marginal se iguala à taxa de juros real internacional $r$. A fronteira intertemporal de possibilidades de produção (PPF) mostra as possibilidades tecnológicas disponíveis em autarquia para transformar o consumo no período 1 em consumo no período 2 . A PPF é descrita pela equação:

$$
C 2=F\left[K_{1}+F\left(K_{1}\right)-C_{1}\right]+K_{1}+F\left(K_{1}\right)-C_{1}
$$

onde $F\left[K_{1}+F\left(K_{1}\right)-C_{1}\right]=Y_{2}$ e $K_{1}+F\left(K_{1}\right)-C_{1}=K_{2}$. 
Em autarquia, quando $C_{2}=F(0)+0=0, C_{1}=K_{1}+F\left(K_{1}\right)$ e quando $C_{1}=0, C_{2}=F\left[K 1+F\left(K_{1}\right)\right]+K_{1}+F\left(K_{1}\right)$. A inclinação da PPF é dada a partir da equação (18), pela seguinte diferenciação: $d C_{2} / d C_{1}=-\left[1+F^{\prime}\left(K_{2}\right)\right]$. Ou seja, a produtividade marginal decrescente do capital implica uma PPF estritamente côncava.

A figura 2 corresponde à figura 1 acrescida da PPF e ilustra os ganhos de bem-estar decorrentes da integração de uma economia aos mercados internacionais de comércio e de capitais. O equilíbrio em autarquia encontra-se no ponto $(A)$ de tangência da PPF com a curva de indiferença mais elevada que se pode alcançar quando a economia não está integrada ao mercado internacional de capitais. Esta tangente tem inclinação - $\left(1+r_{A}\right)$. Quando $r_{A}>r$, o retorno marginal do investimento é superior ao custo do empréstimo de recursos no mercado internacional. Portanto, com a abertura ao mercado internacional de capitais os residentes terão um ganho positivo investindo mais e produzindo bens de consumo no ponto $B$, tangente à nova linha de restrição orçamentária da economia, que é a mais elevada possível aos preços internacionais; ou seja, a linha de restrição orçamentária relevante muda da inclinação $-\left(1+r_{A}\right)$ para $-(1+r)$.

Figura 2

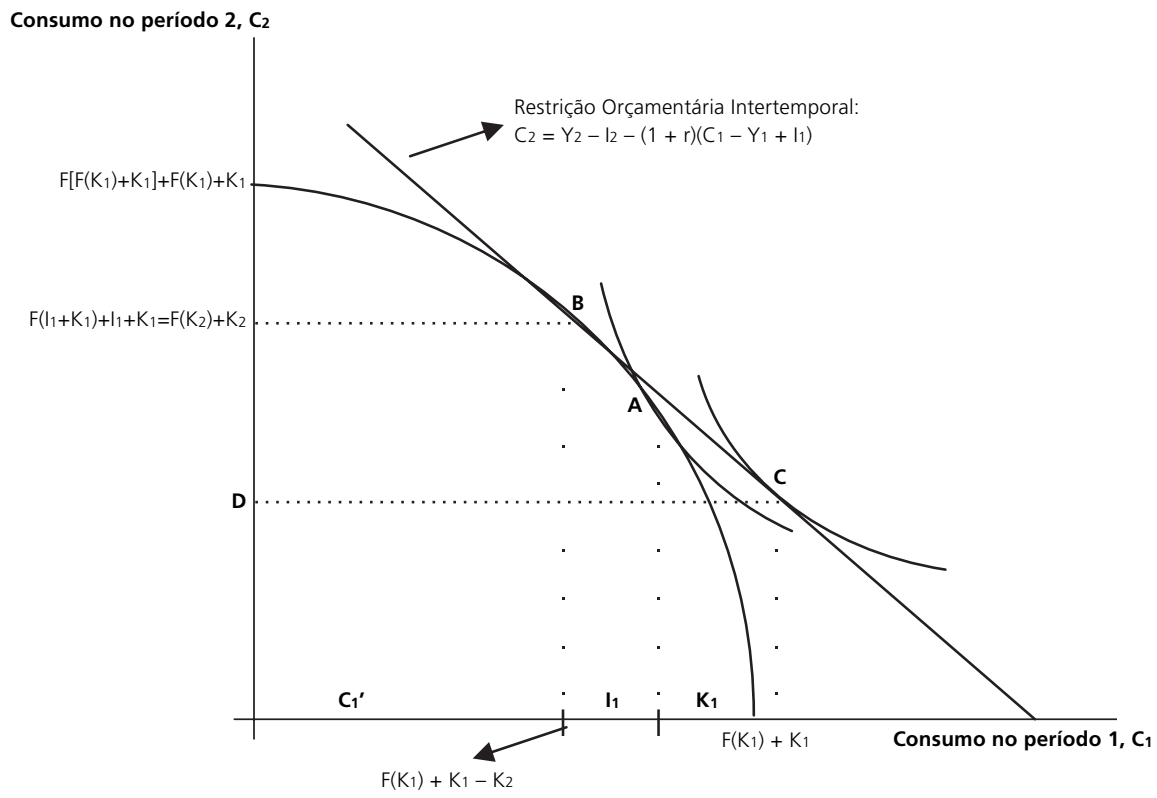


A distância horizontal entre $A$ e $B$ corresponde ao investimento extra gerado pela abertura da economia ao mercado mundial de capitais. A distância horizontal entre $A$ e $C$ mostra o aumento do consumo no período 1. Visto que o total de recursos do período $1\left(Y_{1}+K_{1}\right)$ não se alterou, a soma dessas distâncias - isto é, $B-C$ - corresponde ao déficit em conta corrente no período 1 .

A curva de indiferença que passa por $C$ está acima daquela que passa por A. A distância entre elas mede os ganhos decorrentes da abertura da economia. Na figura 1, os ganhos eram inteiramente devidos à suavização da trajetória temporal do consumo. Na figura 2 há um ganho adicional associado à mudança do ponto de produção de $A$ para $B$. Quando $r_{A}<r$, ocorre o inverso, e o país que se encontrava inicialmente em uma situação de autarquia incorre em um superávit em conta corrente no período 1 e em déficit no período 2, alcançando, da mesma forma, a solvência intertemporal do balanço de pagamentos e os ganhos decorrentes da troca intertemporal. ${ }^{4}$

No que se refere ao modelo de horizonte finito para uma pequena economia, $\mathrm{o}$ agente representativo maximiza:

$$
\begin{aligned}
& U_{t}=u\left(C_{1 t}\right)+\beta \cdot u\left(C_{t+1}\right)+\beta^{2} \cdot u\left(C_{t+2}\right)+\ldots+\beta^{T} \cdot u\left(C_{t+T}\right)= \\
& =\sum_{S=t}^{t+T} \beta^{S-t} \cdot u\left(C_{S}\right)
\end{aligned}
$$

Além disso, $Y=A$. $F(K)$, onde $F(K)$ tem as mesmas propriedades apresentadas anteriormente. $A$ é um coeficiente exógeno de produtividade. A economia inicia na data $t$ com estoques pré-acumulados de capital $K_{t} \mathrm{e}$ ativos externos líquidos $B_{t}$. Como antes, $I_{t}=K_{t+1}-K_{t}$. Assumindo taxas de juros constantes, a conta corrente é dada por:

$$
C A_{t}=B_{t+1}-B_{t}=Y_{t}+r . B_{t}-C_{t}-I_{t}
$$

Rearranjando os termos, temos:

$$
(1+r) \cdot B_{t}=C_{t}+I_{t}-Y_{t}+B_{t+1}
$$

Adiantando esta equação em um período e dividindo ambos os lados por $1+r$, temos $B_{t+1}=\left[\left(C_{t+1}+I_{t+1}-Y_{t+1}\right) /(1+r)\right]+B_{t+2} /(1+r)$, que pode ser usada para eliminar $B_{t+1}$ da equação (21): 


$$
\begin{aligned}
& (1+r) . B_{t}=C_{t}+I_{t}-Y_{t}+\left[\left(C_{t+1}+I_{t+1}-Y_{t+1}\right) /(1+r)\right]+ \\
& +B_{t+2} /(1+r)
\end{aligned}
$$

Podemos repetir esse processo adiantando a equação (21) em dois períodos e dividindo ambos os lados por $(1+r)^{2}$ para eliminar $B_{t+2} /(1+r)$ da equação acima, e assim por diante. Esta seqüência leva à restrição orçamentária intertemporal:

$$
\begin{aligned}
& \sum_{S=t}^{\mathrm{t}+\mathrm{T}}(1 / 1+r)^{S-t} \cdot\left(C_{S}+I_{S}\right)+(1 / 1+r)^{T} \cdot B_{t+T+1}= \\
& =(1+r) \cdot B_{t}+\sum_{S=t}^{t+T}(1 / 1+r)^{S-\mathrm{t}} \cdot \mathrm{Y}_{\mathrm{S}}
\end{aligned}
$$

Para achar o plano consumo/investimento que maximiza $U_{t}$ na equação (19) sujeito à equação (23), isolamos $C_{S}$ da identidade da conta corrente, $B_{S+1}-B_{S}=r . B_{S}+A_{S} . F\left(K_{S}\right)-C_{S}-\left(K_{S+1}-K_{S}\right)$, para substituí-lo na equação (19):

$$
U_{t}=\sum_{S=t}^{\mathrm{t}+\mathrm{T}} \beta^{S-t} \cdot u\left[(1+r) B_{S}-B_{S+1}+A_{S} \cdot F\left(K_{S}\right)-\left(K_{S+1}-K_{S}\right)\right]
$$

As condições de primeira ordem são obtidas a partir da maximização de $U_{t}$ com respeito a $B_{S+1}$ e $K_{S+1}$. Assim, para cada período $s \geq t$, duas condições prevalecem, a saber, a equação de consumo de Euler e aquela que iguala o produto marginal do capital à taxa de juros mundial:

$$
\begin{aligned}
& u^{\prime}\left(C_{S}\right)=(1+r) \cdot \beta \cdot u^{\prime}\left(C_{S+1}\right) \\
& A_{S+1} F^{\prime}\left(K_{S+1}\right)=r
\end{aligned}
$$

Visto que a condição terminal $B_{t+T+1}=0$ deve prevalecer para que o agente representativo não chegue ao final dos tempos na situação de credor ou devedor líquido, a única trajetória de consumo ótimo que satisfaz a equação (25) e a equação (23), com $B_{t+T+1}=0$, é:

$$
\sum_{S=t}^{\mathrm{t}+T}(1 / 1+r)^{S-t} \cdot\left(C_{S}+I_{S}\right)=(1+\mathrm{r}) \cdot B_{t}+\sum_{S=t}^{\mathrm{t}+T}(1 / 1+\mathrm{r})^{S-t} \cdot Y_{S}
$$

Em (27) todos os níveis de investimento e de produto são determinados por (26), dado o capital inicial, $K_{t}$. Portanto, ao maximizar sua função 
utilidade, o agente representativo se localiza em algum ponto da linha de restrição orçamentária intertemporal, cuja inclinação está associada ao nível de $r$, conforme já havia sido constatado no modelo anterior. Ou seja, no modelo de horizonte finito, os mecanismos pelos quais ocorrem os ganhos decorrentes da abertura da economia ao mercado internacional de capitais num contexto de solvência intertemporal do balanço de pagamentos são os mesmos relacionados ao modelo de dois períodos.

No caso do modelo de horizonte infinito, a função utilidade do agente representativo é: ${ }^{5}$

$$
\begin{aligned}
& U_{t}=\sum_{S=t}^{\infty} \beta^{S-t} \cdot u\left(C_{S}\right) \text {; e a equação (24) é maximizada, porém com } T=\infty \\
& U_{t}=\sum_{S=t}^{\infty} \beta^{S-t} \cdot u\left[(1+r) B_{S}-B_{S+1}+A_{S} \cdot F\left(K_{S}\right)-\left(K_{S+1}-K_{S}\right)\right]
\end{aligned}
$$

Maximizando (28) com respeito a $B_{S+1}$ e $K_{S+1}$ teremos novamente (25) e (26). O nível ótimo de consumo em cada data é dado a partir da combinação dessas condições de primeira ordem com a restrição orçamentária intertemporal. Neste caso, a condição de transversalidade é:

$$
\operatorname{Lim}_{T \rightarrow \infty}[1 /(1+r)]^{T} \cdot B_{t+T+1}=0^{6}
$$

A equação (23) juntamente com a imposição de (29) resulta em:

$$
\sum_{S=t}^{\infty}(1 / 1+r)^{S-t} \cdot\left(C_{S}+I_{S}\right)=(1+r) \cdot B_{t}+\sum_{S=t}^{\infty}(1 / 1+\mathrm{r})^{S-t} \cdot Y_{S}
$$
Se $\operatorname{Lim}_{T \rightarrow \infty}[1 /(1+r)]^{T} \cdot B_{t+T+1}<0$, o valor presente da soma do consumo e

investimento excede o valor presente do produto, por um montante que nunca converge para zero. Neste caso, a dívida dessa economia com o resto do mundo cresce, pelo menos, à taxa de juros $r$. Os credores estrangeiros não aceitarão esta situação Ponzi, impondo a condição não-Ponzi, onde $\operatorname{Lim}[1 /(1+r)]^{T} \cdot B_{t+T+1} \geq 0$. No caso oposto, se $\operatorname{Lim}[1 /(1+\mathrm{r})]^{\mathrm{T}} \cdot B_{\mathrm{t}+\mathrm{T}+1}>0$, $\mathrm{T} \rightarrow \infty$ $T \rightarrow \infty$

os residentes domésticos não estarão maximizando sua utilidade, pois o 
valor presente da soma do consumo e investimento será inferior ao valor presente do produto. Somente quando $\operatorname{Lim}[1 /(1+\mathrm{r})]^{\mathrm{T}} \cdot B_{t+T+1}=0$ essa $\mathrm{T} \rightarrow \infty$

maximização se verificará. Portanto, as condições (20), (25), (26) e (29) são necessárias e suficientes para que se encontre o ótimo.

Novamente, os mecanismos pelos quais ocorrem os ganhos decorrentes da abertura da economia ao mercado internacional de capitais num contexto de solvência intertemporal do balanço de pagamentos são os mesmos relacionados ao modelo de dois períodos. Portanto, a avaliação da sua adequação às economias em desenvolvimento pode ser estendida aos demais modelos apresentados e será desenvolvida a seguir.

\section{DIFERENCIAIS DE PRODUTIVIDADE ENTRE ECONOMIAS E O MODELO DE TROCA INTERTEMPORAL}

Esses modelos trabalham com apenas um produto. Assumindo previsão perfeita dos agentes, a suavização do consumo no tempo maximizaria sua utilidade. A hipótese de produto único e idêntico não é apenas uma simplificação da realidade sem implicações para as conclusões do modelo. Ela se baseia no abandono do paradigma de diferencial de produtividade, adotado originalmente em Ricardo (1985). Ao resgatarmos esse paradigma, as diferenças entre economias que guiam as trocas, comerciais e intertemporais, deixam de ser apenas "diferenças de preços", conforme argumento da teoria neoclássica nas suas vertentes do comércio internacional e da troca intertemporal. $^{7}$

Diferenças de produtividade entre economias são observadas e explicadas em vários autores de diferentes escolas econômicas. Cite-se o próprio Ricardo (1985), autores da Cepal tais como Prebisch (2000a, 2000b, 2000c) e Fajnzylber $(1983,1990)$ e autores neoschumpeterianos como, por exemplo, Dosi (1988), Dosi et al. (1994) e Cassiolato e Lastres (1999). Segundo esses autores, diferenças de produtividade (e de capacidade endógena de produção de tecnologia) entre economias resultam em diferenças no leque de bens passíveis de produção competitiva no mercado internacional. Ainda segundo cepalinos e neoschumpeterianos, diferenças de produtividade e de capacidade (endógena) de produção de tecnologia refletem-se em um processo de desenvolvimento desigual entre economias. 
Para que o processo econômico de desenvolvimento desigual, observado empiricamente, seja estudado no contexto da troca intertemporal, o modelo em análise deve ser alterado. É necessário substituir a hipótese de um único bem pela de produção de uma cesta de bens nas economias. Além disso, as cestas de bens trocadas (intertemporalmente) entre centro (países desenvolvidos) e periferia (países não desenvolvidos) seriam distintas, visto que a cesta daquele seria mais diversificada em virtude de seu diferencial tecnológico e de produtividade. Visto que hipóteses do modelo neoclássico foram alteradas, o que se segue não constitui uma crítica interna ao modelo neoclássico apresentado na seção anterior.

A função utilidade do agente representativo continua sendo $U_{1}=u\left(C_{1}\right)$ $+\beta . u\left(C_{2}\right)$, com $0<\beta<1$. Todavia, $\beta$ condensa dois efeitos de naturezas distintas sobre o desconto subjetivo do agente representativo, quando o modelo incorpora a troca entre países de cestas com diferentes graus de variedade de bens. Há o efeito temporal — quanto maior a impaciência do agente para consumir, maior é a sua perda de utilidade quando o consumo é postergado e, portanto, menor é $\beta$ - e há o efeito decorrente da troca de diferentes cestas de bens (essas diferenças não se referem à quantidade, mas, sim, à variedade de bens). Quando uma cesta de bens mais diversificada é exportada pelo centro no período 1 , em $T_{1}$, e o centro importa da periferia uma cesta com menor variedade de bens, em $T_{2}$, o desconto subjetivo do agente representativo é novamente afetado, dado que a satisfação proporcionada pela cesta exportada pelo centro é superior àquela advinda da cesta importada, embora ambas possam conter a mesma quantidade de bens. ${ }^{8}$

Quanto maior é a diferença entre as cestas de bens trocadas, no que se refere à sua diversificação, maior será o desconto subjetivo do agente e menor será $\beta$, seja na periferia ou no centro. E quanto menor for $\beta$, mais inclinadas serão as curvas de indiferença no modelo de troca intertemporal. Neste caso, a equação de Euler poderia ser satisfeita; porém, uma vez que $\beta$ seria menor, a maximização da utilidade do agente representativo se daria a partir de um aumento do nível de consumo presente $C_{1}$, e de uma queda do nível de consumo futuro $C_{2}$, de tal sorte que a igualdade $u^{\prime}\left(C_{1}\right)=(1+\mathrm{r}) \cdot \beta$ . $u^{\prime}\left(C_{2}\right)$ permanecesse válida. Ou seja, a redução de $\beta$ provoca uma mudança no equilíbrio da mesma forma que uma redução na taxa de juros externa $r$. Em termos da figura 1, quando $\beta$ se reduz, o equilíbrio se dá em um ponto 
abaixo de $C$, ponto $C^{\prime}$ na reta de restrição orçamentária - com o aumento da inclinação da curva de indiferença, esta será tangente à reta de restrição orçamentária em $C^{\prime}$ em vez de $C$, satisfazendo a equação de Euler.

Contudo, a mudança no nível de bem-estar do agente representativo não pode ser mensurada: na periferia, o equilíbrio do agente representativo em situação de autarquia se dava no ponto $A$, de tangência da reta de restrição orçamentária de inclinação - $\left(1+r_{A}\right)$ com uma curva de indiferença. Além disso, numa economia em autarquia, as cestas de consumo produzidas e demandadas nos períodos 1 e 2 têm exatamente o mesmo grau de diversificação (se supusermos que não haverá ganhos de produtividade durante os períodos 1 e 2). Mas a existência de diferenciais de produtividade entre centro e periferia implica redução de $\beta$ e aumento da inclinação das curvas de indiferença no contexto da integração da economia ao mercado internacional de capitais. Assim, surgiria um novo ponto de equilíbrio, $C^{\prime}$. Os níveis de bem-estar verificados na situação de equilíbrio autárquico e na situação de equilíbrio que se observa após a abertura da economia aos fluxos de capitais (e à redução de $\beta$ ) estão representados pelos níveis das curvas de indiferença que passam pelos pontos $A$ e $C^{\prime}$, respectivamente. Contudo, essas curvas de indiferença se cruzarão, visto que possuem inclinações diferentes, não permitindo mensurar a mudança do bem-estar do agente representativo após a integração da economia ao mercado mundial de capitais num contexto de diferenciais de produtividade entre os países (ver figura 3).

Figura 3

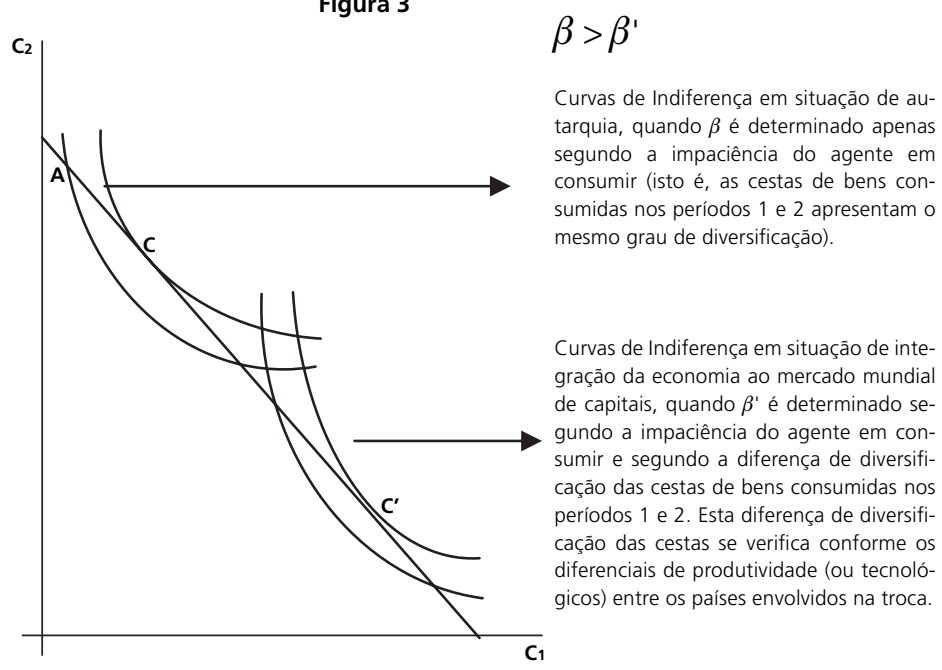


Ademais, esse equilíbrio no ponto $C^{\prime}$ só seria possível quando as diferenças do grau de desenvolvimento tecnológico entre os países fossem estáticas (ou constantes). Porém, elas podem aumentar ou diminuir ao longo do tempo, isto é, são dinâmicas. De acordo com a figura 1, no comércio intertemporal entre centro e periferia, no período $1, T_{1}$, o centro incorre em um superávit e a periferia em déficit na conta corrente. Mas o valor futuro de $\beta$ não pode ser conhecido previamente pelos agentes. Assumindo a hipótese (que não se verifica necessariamente) de que entre os períodos $T_{1}$ e $T_{2}$ o centro apresentará maior taxa de desenvolvimento de sua produtividade (ou tecnológico) vis-à-vis à periferia, as curvas de indiferença dos agentes, seja no centro, seja na periferia, se inclinarão durante o processo de troca intertemporal. Porém, somente em $T_{2}$ a nova inclinação dessas curvas (ou a magnitude da redução de $\beta$ ) será conhecida. Mas em $T_{2}$, o tamanho do superávit no centro e do déficit na periferia, verificados em $T_{1}$, já foi dado segundo a diferença inicial de produtividade, conhecida pelos agentes (isto é, segundo o valor inicial de $\beta$ ). Visto que não há nenhuma regra que determine a exata trajetória temporal da mudança dos diferenciais de produtividade entre os países, os agentes não podem conhecer ex-ante as variações de $\beta$. Isto é, o mundo de previsão perfeita dos agentes está sendo substituído pelo da incerteza. ${ }^{9}$ Neste caso, a maximização da função utilidade fica inviabilizada. Em suma, o agente representativo não pode maximizar sua utilidade segundo a equação de Euler, visto que num processo temporal $\beta$ deixa de ser parâmetro e torna-se variável. ${ }^{10}$

Outra crítica ao modelo de troca intertemporal que surge quando os diferenciais de produtividade entre países são incorporados ao modelo se refere ao formato das curvas de indiferença, que são bem comportadas no modelo convencional.

A natureza das diferenças entre os coeficientes de importação do centro e da periferia associa-se à capacidade de um e de outro de produzir maior variedade (e não quantidade) de bens. ${ }^{11}$ Sendo assim, não basta compensar a poupança realizada pelo centro no período 1, e absorvida pela periferia, com uma maior quantidade de bens exportados desta para o centro no período 2, visto que a demanda de ampla gama de produtos (bens intermediários e de capital) no centro, imprescindíveis ao seu processo de acumulação, não pode ser satisfeita pela periferia. Neste caso, é possível que exista um 
ponto de saciedade para as importações de bens produzidos na periferia e demandadas pelo centro - o que é compatível com sua baixa elasticidaderenda da demanda de importações por bens da periferia, conforme enfatizava Prebisch (2000b). Esse ponto de saciedade determinaria um limite para o déficit em conta corrente do centro (e, portanto, para o superávit na periferia) a partir do qual o nível de bem-estar do agente do centro se reduziria. Neste caso, as curvas de indiferença seriam representadas por círculos, sendo que quanto menor o seu diâmetro, maior o nível de bem-estar do consumidor (figura 4). ${ }^{12}$

Se o ponto de saciedade correspondesse, por exemplo, ao equilíbrio em autarquia no centro, a troca intertemporal nem ocorreria. Mais precisamente, o agente representativo só alcançaria o ponto de maximização de sua utilidade previsto no modelo de um único bem e com curvas de indiferença bem comportadas se esse ponto coincidisse com seu ponto de saciedade. Assim, embora a periferia possa gerar uma oferta de exportações mais elevada visando ao saldo em transações correntes necessário para liquidar, no período 2, seus débitos com o centro, a demanda (do centro) por suas exportações não crescerá necessariamente. A lei de Say pode não se verificar e as exportações não ocorreriam automaticamente (necessariamente), como no modelo de um só bem. Esta situação se expressaria em reduzidas elasticidades-preço e renda da demanda de exportações na periferia vis-à-vis ao centro, conforme argumentava a Cepal. ${ }^{13}$

Figura 4

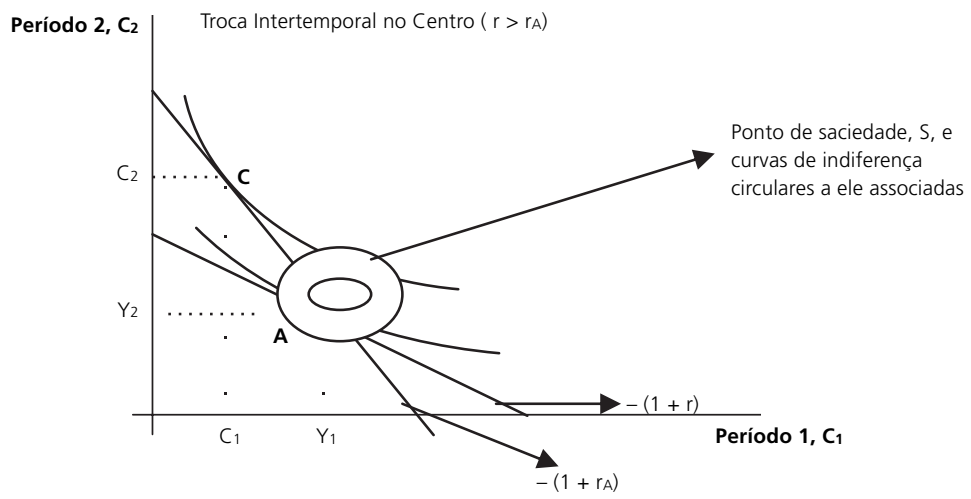


Portanto, no âmbito do modelo de troca intertemporal, mas com a produção de diferentes cestas de consumo pelas economias, o excedente exportável gerado pela periferia para financiar seus déficits iniciais em transações correntes tende a não encontrar a demanda correspondente no mercado internacional quando esse excedente exportável ultrapassa o ponto de saciedade do centro. Se isto ocorre, a periferia não alcança a condição não Ponzi, requerida para se obter o equilíbrio no modelo de horizonte infinito, e o fluxo de financiamento de seus déficits em transações correntes fica ameaçado, abrindo-se espaço para ataques especulativos contra sua moeda. $\mathrm{O}$ ajuste externo relacionado ao excedente exportável não realizado se dá então em cima do controle das importações e, em última instância, por meio da queda do nível da atividade econômica.

Porém, se há um ponto de saciedade para as importações demandadas pelo centro dos bens produzidos na periferia, surge uma dúvida. Por que, no período 1, seu agente representativo incorreria em superávits na conta corrente e, no período 2, em déficits que estariam além desse ponto de saciedade, em seu processo de troca intertemporal com a periferia? Do mesmo modo, por que a periferia alcançaria déficit em conta corrente cujo financiamento seria saldado com superávit externo superior àquele associado ao ponto de saciedade do centro? Isto ocorreria por pelo menos dois motivos: (i) pela mesma razão que ocorre no modelo convencional — os agentes abandonaram a teoria do valor trabalho e o paradigma ricardiano do diferencial de produtividade de modo que não esperam, inicialmente, a presença de curvas de indiferença circulares no processo de troca intertemporal entre centro e periferia. Ou seja, não esperam que a periferia não consiga gerar os superávits em conta corrente requeridos para financiar seu déficit inicial; (ii) dado que no centro os agentes assumem curvas de indiferença circulares (ou, se quiser, seguem uma perspectiva histórica, aprendendo com o passado de recorrentes crises cambiais na periferia), então eles consideram a possibilidade de a periferia não atender à condição não Ponzi. Neste caso, num modelo com vários países no centro, seus agentes tendem a aumentar os financiamentos à periferia nos momentos de elevada liquidez internacional e à taxa internacional de juros acrescida de um spread que compensa o risco-país, e esperam liquidar seus créditos individualmente antes que se generalize a percepção de que as exportações e os superávits em 
transações correntes da periferia não estão ocorrendo segundo a trajetória associada à sua condição não Ponzi. Daí o surgimento de ataques especulativos contra moedas de países periféricos devedores, como foram os casos recentes do México (1994), Sudeste Asiático (1997), Rússia (1998), Brasil (1999) e Argentina (2001).

Por fim, o equilíbrio demonstrado no modelo de dois períodos com acumulação de capital pode ser rompido, no contexto de diferenciais de produtividade entre países. Neste caso, as relações entre investimento, elasticidade-renda da demanda por importação e coeficiente de importação estão no centro da análise.

Quanto menos desenvolvida for uma economia, mais especializada ela será na produção de poucos bens. Assim, se a economia sai da situação de autarquia, seu coeficiente de importação tende a ser tanto maior que o de exportação quanto menos desenvolvida ela for — ou quanto menores forem seus graus de desenvolvimento tecnológico e de produtividade em relação às demais economias. Além disso, no processo de acumulação de capital em economias abertas menos desenvolvidas verifica-se a necessidade de importação de uma gama significativa de bens requerida para o processo de produção, e que se reflete em sua elasticidade-renda da demanda de importação. Assim, numa economia aberta, essa elasticidade será tanto maior quanto menos desenvolvida for essa economia. ${ }^{14}$ Se a elasticidade-renda da demanda de importações é maior do que 1, então, quanto maior for a taxa de investimento em determinado período, maior será a taxa de crescimento do produto, e uma taxa ainda maior será observada para o crescimento das importações, resultando num aumento do coeficiente de importação nesse período.

Portanto, quando a economia periférica sai da situação de autarquia comercial e financeira, ela tende a apresentar déficits comerciais e que serão tanto maiores quanto maiores forem as taxas de investimento e de crescimento do produto no período. Porém esses déficits nada têm a ver com meras escolhas sobre trocas intertemporais de agentes maximizadores de sua função utilidade. Ao contrário do que sugere o modelo apresentado em Obstfeld e Rogoff (1996), o tamanho do saldo em transações correntes (negativo ou positivo) nem sempre é uma questão de escolha ótima dos agentes sobre a magnitude do aumento relativo (positivo ou negativo) da absorção 
doméstica no período em consideração, dada sua restrição orçamentária intertemporal. $\mathrm{Na}$ interpretação alternativa que está sendo proposta, dada a abertura da economia, os tamanhos dos coeficientes de importação e de exportação, como também os saldos em conta corrente, dependem do seu grau de desenvolvimento, entre outros fatores tais como as taxas de investimento e de crescimento da renda.

No modelo de dois períodos com acumulação de capital (figura 2), quando a economia vai se integrar ao mercado mundial de capitais os agentes produzem níveis de bens de consumo, nos períodos 1 e 2 , associados ao ponto $B$ da figura 2. A partir de então, visando maximizar sua utilidade, estabelecem a troca intertemporal com o resto do mundo consumindo bens nos níveis representados pelo ponto $C$, nos períodos 1 e 2 . A distância horizontal $A$ - $B$ corresponde ao aumento dos investimentos no período 1 e, portanto, está associada à taxa de crescimento da economia, enquanto a distância horizontal $B-C$ representa o déficit em transações correntes nesse período.

Quando a economia passa de $A$ para $B$, a produção total no período 1 não se altera. Sua composição é que muda, visto que parte do estoque de capital, $K_{1}$, destinada à produção de bens de consumo se desloca para a produção de mais capital. A produção total de capital no período $1, I_{1}$, somada ao estoque de capital (não consumido) nesse período, determina o nível do estoque de capital no período $2, K_{2}=I_{1}+K_{1}$.

No contexto de diferenciais de produtividade, parcela da oferta agregada global (produção + importações) verificada na situação de autarquia do modelo convencional mostra-se não competitiva (no mercado internacional) após a abertura comercial e financeira da economia periférica. ${ }^{15}$ Isto ocorre porque a incorporação dos diferenciais de produtividade ao modelo implica eliminar as hipóteses de igual função de produção para os países e de produção de um único e idêntico bem nesses países. O diferencial tecnológico e a produção mais diversificada no centro provocam na periferia a reorientação da demanda interna por importações de bens de consumo e de capital (em um nível superior ao da ocorrência das suas exportações), tornando parcela do estoque de capital das economias periféricas obsoleta, por não ser competitiva. Assim, após a abertura da economia periférica, parte da produção de bens de consumo e de capital é substituída por importações e 
a parcela do estoque de capital que em autarquia produzia esses bens substituídos desaparece. ${ }^{16}$

Deste modo, independentemente do ponto sobre a fronteira de possibilidades de produção (PPF) para o qual o agente representativo se deslocar após a abertura comercial e financeira da economia periférica, a PPF sofrerá uma redução (encolhimento) decorrente do "desaparecimento" de parcela do estoque de capital. ${ }^{17}$ Contudo, se para evitar a perda de utilidade do agente representativo a oferta agregada global (produção + importações) não for reduzida após o encolhimento da PPF, parcela da oferta agregada que no período anterior à abertura da economia periférica se realizava apenas a partir da produção doméstica será realizada a partir de importações, antes mesmo de o agente representativo iniciar a troca intertemporal de consumo, visando maximizar sua utilidade.

Exemplificando, se o agente representativo se localizar no ponto $B$ da figura 2 após a abertura da economia periférica, no período 1 , as ofertas agregadas de bens de consumo (representada por $C_{1}{ }^{\prime}$ ) como também de bens de capital (representada por $I_{1}$ ) (figura 2) não se realizarão apenas a partir da produção doméstica como ocorre no modelo convencional (isto é, sem a incorporação de diferenciais de produtividade entre países) mas, também, a partir de importações. ${ }^{18}$ Isto ocorre quando, após o desaparecimento de parcela do estoque de capital decorrente da abertura, o agente representativo substitui parte da produção doméstica (não competitiva) por importações visando evitar a perda de utilidade. Esta também seria evitada se o agente pudesse "comer" (ou dar usos alternativos para) a parcela do estoque de capital não competitiva. ${ }^{19}$ Essa "perda de capital" teria uma correspondência com a perda de utilidade do agente representativo na medida em que a produção é função do estoque de capital, $Y=F(K)$.

Se parte do estoque de capital da economia periférica desaparece no processo de substituição da produção interna por importações, quanto maiores forem essas importações que não decorrem da troca intertemporal do consumo (isto é, podem ser consideradas anteriores a este processo), maior será o déficit em transações correntes no período 1 . Num modelo de dois períodos, o financiamento das importações terá de ser saldado no período 2 , reduzindo-se o espaço para a troca intertemporal entre $C_{1}$ e $C_{2}$. Neste caso, o nível de utilidade dos agentes pode até ser menor do que aquele 
observado na situação inicial de autarquia, no ponto A. No caso-limite em que no período 1 toda a produção interna de $C_{1}$, dada por $C_{1}$ ' na figura 2, é substituída por importações e toda a produção interna de capital, $I_{1}$, também é substituída por importações, se os níveis de consumo $C_{1}$ e $C_{2}$ estão associados ao ponto $C$ da figura 2 , então o nível das importações que não correspondem mais à distância horizontal $B$ - $C$, como ocorre no modelo de um único bem, mas à soma das distâncias horizontais $D$ - $C$ (importação de bens de consumo) e $B$ - $A$ (importação de bens de capital) implicará desequilíbrio intertemporal do balanço de pagamentos ou, mantendo-se a solvência intertemporal externa, redução dos níveis de $C_{1}$ e/ou de $C_{2}$ e, portanto, do nível de utilidade dos agentes. Ou seja, para satisfazer a solvência do balanço de pagamentos, a troca intertemporal do consumo entre uma economia do centro e outra periférica, se houver, não resultará no ponto de equilíbrio $C$, conforme sugere o modelo convencional. Do mesmo modo, ela não implicará, necessariamente, ganhos de utilidade e bem-estar para os agentes envolvidos.

Em outras palavras, no período 2, na medida em que $K_{1}$ desaparece, o único estoque de capital disponível corresponde às importações de bens de capital $\left(I_{1}\right)$ verificadas no período $1: Y_{2}=F\left(I_{1}\right), K_{2}=I_{1}+0$. Visto que o capital do período 2 é importado, é possível que a periferia obtenha ganhos de produtividade e, assim, alcance um aumento em $Y_{2}$, isto é, $F^{\prime}\left(I_{1}\right)$ cresce quando " $I_{1}$ é importado". Porém, a solvência intertemporal do seu balanço de pagamentos, mantidos os níveis de consumo associados ao ponto $C \mathrm{da}$ figura 2, requer um crescimento de $Y_{2}$ elevado o suficiente para, depois de deduzido $C_{2}$ de $Y_{2}$, gerar um superávit externo cuja magnitude é dada pela soma das importações de bens de consumo (distância horizontal $D-C$ ) e de bens de capital (distância horizontal $B$ - $A$ ) e dos juros que incidem sobre o financiamento externo dessas importações. Porém, somente importar bens de capital não é suficiente para se obterem ganhos de produtividade e de competitividade internacional.

(...) tecnologias não podem ser pegas na prateleira e simplesmente serem colocadas em uso em algum lugar. Sem investimento infra-estrutural em educação, treinamento, pesquisa e desenvolvimento (P\&D), e em outras atividades científicas e tecnológicas, muito pouco pode ser conseguido via aquisição de tecnologias importadas. A aquisição de novas tecnologias é um 
complexo e difundido processo de aprendizado em todos os níveis da sociedade envolvendo inovações sociais e tecnológicas. (Dosi et al., 1994: 28-29)

Fanjzylber (1983) também apresenta argumento para a necessidade de se endogeneizar a produção de tecnologia numa economia como a única forma de esta alcançar a competitividade internacional e um balanço de pagamentos estruturalmente superavitário. Por fim, sem a presença de um "complexo de serviços" desenvolvido, as importações de bens de capital sofisticados tecnologicamente têm pequeno efeito sobre os ganhos de produtividade e de competitividade da produção periférica (Lemos, 1988). De fato, se não fosse assim, os problemas de competitividade e de insolvência (crises) do balanço de pagamentos das economias subdesenvolvidas já teriam sido superados há muito tempo por meio da importação de bens de capital sofisticados.

\section{CONCLUSÕES}

Neste artigo foram alteradas algumas hipóteses do modelo neoclássico de troca intertemporal visando (i) resgatar o paradigma de diferenciais de produtividade entre economias, encontrado em diversas escolas tais como a ricardiana, cepalina e neo-schumpeteriana; (ii) avaliar a adequação desse modelo no âmbito do citado paradigma; (iii) avaliar a capacidade do modelo de explicar quer as possibilidades de solvência intertemporal do balanço de pagamentos das economias em desenvolvimento, quer mudanças no bemestar, decorrentes da integração dessas economias ao mercado mundial de capitais. $^{20}$

Para resgatar o paradigma de diferenciais de produtividade, a hipótese de um único bem foi substituída pela de cestas de bens com diferentes graus de diversificação. Neste caso, demonstrou-se que não é possível mensurar, a partir do citado modelo, mudanças no bem-estar decorrentes da integração de uma economia ao mercado mundial de capitais. Além disso, quando se incorporam ao modelo cestas diferenciadas de bens, o mundo de previsão perfeita dos agentes é substituído pelo da incerteza no sentido pós-keynesiano. Assim, a maximização da função utilidade fica inviabilizada. Em suma, o agente representativo não pode maximizar sua utilidade segundo a equação de Euler, visto que num processo temporal $\beta$ deixa de ser parâmetro e torna-se variável. 
Outra crítica ao modelo de troca intertemporal que surge quando os diferenciais de produtividade entre países são incorporados ao modelo se refere ao formato das curvas de indiferença, que são bem comportadas no modelo convencional. Se há um ponto de saciedade para as importações de bens produzidos na periferia e demandados pelo centro, então as curvas de indiferença dos seus agentes seriam representadas por círculos. Neste caso, há um limite para o déficit em conta corrente do centro (e, portanto, para o superávit na periferia) a partir do qual o nível de bem-estar do agente do centro se reduziria. Se isto se verifica, uma economia periférica pode não alcançar a condição não Ponzi, requerida para se obter o equilíbrio no modelo de horizonte infinito, e o fluxo de financiamento de seus déficits em transações correntes fica ameaçado, favorecendo ataques especulativos contra sua moeda.

Por fim, ao resgatar o paradigma de diferenciais de produtividade (e de desenvolvimento tecnológico) entre economias, constata-se que, ao contrário do que sugere o modelo apresentado em Obstfeld e Rogoff (1996), o tamanho do saldo em transações correntes (negativo ou positivo) nem sempre é uma questão de escolha ótima dos agentes, dada sua restrição orçamentária intertemporal. Ademais, na interpretação alternativa que está sendo proposta, a abertura de uma economia não desenvolvida provoca a obsolescência de parcela do seu estoque de capital e, portanto, perda de utilidade para o agente representativo, se ele não pode "comer" a parcela do estoque de capital não competitiva. Deste modo, a integração de uma economia periférica ao mercado mundial de capitais não garante, necessariamente, ganhos de bem-estar concomitantes à solvência intertemporal de seu balanço de pagamentos.

\section{NOTAS}

1. Neste modelo, uma economia pequena (aberta) é aquela que toma como exógena a trajetória da taxa de juros internacional. Neste caso, estamos abstraindo considerações sobre o equilíbrio geral global, já que elas apenas tornariam a análise mais complexa, mas não afetariam os resultados principais do modelo. Ademais, a maioria dos países corresponde a economias pequenas. Sobre o agente representativo, ver Obstfeld e Rogoff (1996: 3).

2. Sobre a equação de Euler, ver Chiang (1992: 28-36).

3. A soma $Y_{t}+r . B_{t}$ corresponde ao Produto Nacional Bruto (PNB). O consumo, $\mathrm{C}_{\mathrm{t}}$, representa a absorção doméstica. 
4. Este modelo supõe que a economia em questão é pequena, visto que toma a trajetória temporal da taxa de juros internacional como exógena. Este é o caso da maioria das economias, especialmente as periféricas. $\mathrm{O}$ caso da economia grande está tratado, por exemplo, em Obstfeld e Rogoff (1996: 23-25). Neste caso, ao afetar a trajetória da taxa de juros internacional, a economia terá ganhos decorrentes de sua abertura ao mercado de capitais internacional, mas estes podem ser aumentados ou amenizados, dependendo se a taxa de juros irá aumentar ou cair e se a economia incorre em déficit ou superávit em transações correntes no período 1.

5. Sobre a aplicação do modelo de horizonte infinito para o conhecimento da sustentabilidade de déficits em conta corrente na economia brasileira, ver, por exemplo, Maka (1997).

6. Sobre a condição de transversalidade, ver Chiang (1992: 59-68).

7. Os princípios básicos da denominada teoria pura do comércio internacional foram formulados por Heckscher e Ohlin ( $\mathrm{H}-\mathrm{O})$ e seu formato analítico foi desenvolvido posteriormente por Samuelson. H-O alteram o ponto de partida do estudo ricardiano do comércio internacional, alcançando proposições distintas sobre o comércio. Ver, por exemplo, Ohlin (1966), Williamson (1989) e Krugman e Obstfeld (2001). Críticas a esse modelo estão, por exemplo, em Davis (1996), Dosi (1988), Resende (2003) e Lemos (1988: 209-215). Este último apresenta formalmente a indeterminação da taxa de câmbio em Ohlin. A correlação positiva entre orientação comercial e desempenho econômico não é consensual na literatura (Edwards, 1993).

8. Sendo assim, em termos da equação de Euler (3), teríamos para a economia do centro $u^{\prime}\left(C_{2}{ }^{i}\right)<u^{\prime}\left(\mathrm{C}_{2}{ }^{j}\right)$, onde $C_{2}{ }^{i}$ é a quantidade do único (tipo de) bem consumido no período 2 no modelo de um só bem, e $C_{2}{ }^{j}$ é uma cesta de consumo que apresenta a mesma quantidade de bens encontrada em $C_{2}{ }^{i}$, porém com um grau de variedade maior, não se limitando a um único tipo de bem.

9. O conceito de incerteza está definido na literatura pós-keynesiana e difere do conceito de risco. Ver, por exemplo, Dow (1985: 184-203), Carvalho (1992: 54-69), Amado (2000: 47-55) e Crocco (2002).

10. Nesse modelo "dinâmico" de troca intertemporal que está sendo proposto pode ocorrer uma perda do poder relativo da cesta de bens produzidos na periferia em satisfazer o consumidor. Sempre que aumenta o diferencial de produtividade entre o centro e a periferia, $\beta$ se reduz e a inclinação das curvas de indiferença aumenta. Curvas de indiferença mais inclinadas implicam que, para que os agentes permaneçam com o mesmo nível de satisfação quando trocam (intertemporalmente) o consumo, uma cesta de bens exportada do centro para a periferia em $T_{1}$ deve ter como contrapartida outra cesta com maior quantidade de bens exportada da periferia para o centro, em $T_{2}$, vis-à-vis à cesta que deveria ser exportada caso o aumento do diferencial de produtividade não ocorresse. Ou seja, a redução de $\beta$ induzida pelo aumento desse diferencial expressa a queda do poder relativo da cesta de bens produzidos na periferia em satisfazer o consumidor. Em termos da figura 1, esse processo está representado na mudança de equilíbrio do ponto $C$ para $C^{\prime}$. 
11. Se há alguma dúvida sobre este ponto, ver Lemos (1988).

12. Sobre o ponto de saciedade e o formato em círculo das curvas de indiferença, ver Varian (1994: 47- 48).

13. Sobre os motivos para a reduzida magnitude dessas elasticidades na periferia ver, por exemplo, Prebisch (2000b: 185-189).

14. A abertura comercial brasileira, iniciada timidamente em 1988, e que ganhou ímpeto a partir de 1990, é um exemplo eloqüente dessa questão: a elasticidade-renda da demanda de importação subiu de 0,54 nos anos 80 para 3,85 após 1990 (Resende, 2001) e, no mesmo período, de não significativa para 2,1 (Azevedo e Portugal, 1998). Sobre este ponto, ver, para o caso recente da economia brasileira, Resende e Anderson (1999).

15. No equilíbrio em autarquia, a oferta agregada global $=$ produto interno bruto $=$ produto nacional bruto. Sobre esses conceitos, ver Lopes e Vasconcellos (1998: 31-46).

16. Ou seja, excluindo-se a hipótese de que $K_{1}$ pode ser "comido" e que, segundo Obstfeld e Rogoff (1996: 15), “é irrealista mas não altera as conclusões do modelo", parte de $K_{1}$ simplesmente desaparece. Note, ainda, que não estão sendo consideradas as importações que não ocorrem em substituição à produção doméstica no sentido de que são bens "novos", posto que não eram produzidos quando a economia era fechada.

17. Segundo Obstfeld e Rogoff (1996), o agente representativo se deslocará do ponto $A$ da figura 2 para o $B$, para então realizar a troca intertemporal de consumo e localizar-se em $\mathrm{C}$, visando maximizar sua utilidade.

18. Ademais, essas importações serão tanto maiores quanto maior for a elasticidade-renda da demanda de importações e quanto maior for a taxa de investimento no período.

19. Segundo o modelo H-O, haveria um uso alternativo para esse capital: seu deslocamento para a produção de bens exportáveis pertencentes aos setores eficientes da economia. Assim, após a abertura, o surgimento de importações seria compensado pelo aparecimento de exportações. Todavia, esse resultado não se observa necessariamente, conforme argumentam Fanjzylber (1983, cap. 5), Dosi (1988) e Lemos (1988). Segundo Dosi (1988: 130-133), quanto maior for a distância da economia em relação à fronteira tecnológica, maior é a possibilidade de surgimento de trade-offs entre a eficiência alocativa e as eficiências "schumpeteriana" e de "crescimento". Edwards (1993) apresenta um survey da literatura sobre o comércio internacional e constata que a correlação positiva entre abertura comercial e desempenho econômico não é consensual. Por fim, o argumento aqui desenvolvido está relacionado com o anterior. Se há um ponto de saciedade para a importação pelo centro de bens produzidos pela periferia, conforme se depreende da análise de autores cepalinos e neo-schumpeterianos, então há limites para o aumento das exportações da periferia. Sendo assim, a abertura econômica nos países periféricos pode resultar em crescimento das importações não acompanhado pelo aumento das exportações na mesma proporção. Neste caso, parcela do estoque dos fatores de produção fica "desempregada" - ou, caso se prefira, torna-se obsoleta e, é claro, não pode ser "comida".

20. Na medida em que hipóteses do modelo neoclássico foram alteradas, esse estudo não representa uma crítica interna ao citado modelo. Ademais, não se pretendeu neste estudo 
desenvolver formalmente outro modelo de troca intertemporal que incorporasse diferenciais de produtividade entre economias, mas tão-somente verificar a adequação do modelo original a um mundo onde os citados diferenciais de produtividade estão presentes.

\section{REFERÊNCIAS BIBLIOGRÁFICAS}

AMADO, A. M. (2000) "Limites monetários ao crescimento: Keynes e a não-neutralidade da moeda”. Porto Alegre, Ensaios FEE, ano 21, n. 1.

AZEVEDO, A. F. Z., PORTUGAL, M. S. (1998) "Abertura comercial brasileira e instabilidade da demanda de importações”. Belo Horizonte, Nova Economia, v. 8, n. 1, jul.

BARRO, R. J., MANKIW, N. G., SALA-I-MARTIN, X. (1992) “Capital mobility in neoclassical models of growth". Yale University, Discussion Paper n. 655, March.

CARVALHO, F. J. C. (1992) Mr Keynes and the Post-Keynesians: principles of macroeconomics for a monetary production economy. Londres: Edward Elgar.

CASSIOLATO, J. E., LASTRES, H. M. M. (1999) Globalização e inovação localizada: experiências de sistemas locais no Mercosul. Brasília: IBICT/MCT.

CHIANG, A. C. (1992) Elements of Dynamic Optimization. Nova York: McGraw-hill.

CROCCO, M. (2002) "The concept of degrees of uncertainty in Keynes, Shackle, and Davidson”. Belo Horizonte, Nova Economia, 12 (2), jul.-dez.

DAVIS, R. D. (1996) “Trade liberalization and income distribution”. Cambridge, NBER Working Paper, n. 5.693, Ago.

DOSI, G. (1988) “Institutions and markets in a dynamic world”. The Manchester School, v. LVI, n. 2, p. 119-146.

DOSI, G., FREEMAN, C., FABIANI, S. (1994) “The process of economic development: introducing some stylized facts and theories on technologies, firms and institutions". Oxford, Industrial and Corporate Change.

DOW, S. C. (1985) Macroeconomic Thought: a methodological approach. Oxford: Blackwell.

EDWARDS, S. (1993) “Openness, trade liberalization, and growth in developing countries". Journal of Economic Literature, v. XXXI, Sept.

FAJNZYLBER, R. F. (1983) La industrialización trunca de América Latina. México: Nueva Imagem.

— (2000) “Da caixa preta ao conjunto vazio, 1990”. In: R. Bielschowsky (org.), Cinqüenta anos de pensamento na CEPAL.

KRUGMAN, P., OBSTFELD, M. (2001) Economia internacional: teoria e política. São Paulo: Makron Books.

LEMOS, M. B. (1988) Espaço e capital: um estudo sobre a dinâmica Centro x Periferia. Tese de doutoramento apresentada ao Instituto de Economia da Universidade Estadual de Campinas.

LOPES, M. L., VASCONCELLOS, M. A. S. (org.) (1998) Manual de macroeconomia básico e intermediário. São Paulo: Atlas. 
MAKA, A. (1997) “A sustentabilidade de déficits em conta-corrente”. Texto para discussão. Brasília: Ipea.

OBSTFELD, M., ROGOFF, K. (1996) Foundations of International Macroeconomics. MIT Press.

OHLIN, B. (1966) Comercio internacional y internacional. Barcelona: Oikos-tau.

PREBISCH, R. (2000a) “O desenvolvimento econômico da América Latina e alguns de seus problemas principais”. In: R. Bielschowsky (org.), Cinqüenta anos de pensamento na Cepal. Rio de Janeiro: Record.

- (2000b) "Problemas teóricos e práticos do crescimento econômico". In: R. Bielschowsky (org.), Cinqüenta anos de pensamento na Cepal. Rio de Janeiro: Record.

(2000c) "Por uma dinâmica do desenvolvimento latino-americano". In: R. Bielschowsky (org.), Cinqüenta anos de pensamento na Cepal. Rio de Janeiro: Record.

RESENDE, M. F. C. (2001) “Crescimento econômico, disponibilidade de divisas e importações no Brasil: um modelo de correção de erros”. Pesquisa e Planejamento Econômico, v. 31, n. 2, ago.

RESENDE, M. F. C. (2003) “Inserção internacional, arranjos financeiros e crescimento na economia brasileira”. Tese de doutorado. Brasília: Departamento de Economia, Universidade de Brasília (UnB).

RESENDE, M. F. C., ANDERSON, P. (1999) "Mudanças estruturais recentes de na indústria de bens de capital. Belo Horizonte”. Nova Economia, v. 9, n. 2, dez.

RICARDO, D. (1985) Princípios de economia política e tributação. São Paulo: Nova Cultural (Coleção Os Economistas).

SIMONSEN, M. H., CYSNE, R. P. (1995) Macroeconomia. São Paulo: Atlas.

VARIAN, R. (1994) Microeconomia. Rio de Janeiro: Campus.

WILLIAMSON, J. (1989) A economia aberta e a economia mundial. Rio de Janeiro: Campus. 